\title{
HUBUNGAN ANTARA LINGKUNGAN KERJA DAN KERJASAMA TIM DENGAN KEPUASAN KERJA
}

\author{
( Studi Korelasional pada Guru Raudhatul Athfal \\ di Wilayah Duren Sawit Jakarta Timur )
}

\author{
Marliza Oktapiani*
}

\begin{abstract}
The Objectivity of study is to examine the work Environment and Teamwork in improving to lecture's job satisfaction teacher's at Raudhatul Athfal of Duren Sawit region east Jakarta. In this study, the method applied is descriptive quantitative method. Analysis unit refers lecture's job satisfaction at Raudhatul Athfal of Duren Sawit region east Jakarta . Instrument applied in collecting of data it is questioner.This study covers: (1) is the work Environment lecture's job satisfaction teacher's at Raudhatul Athfal (2). Is the Teamwork in improving to lecture's job satisfaction teacher's at Raudhatul Athfal and (3) Are the work Environment and Teamwork in collective improving to lecture's job satisfaction teacher's at Raudhatul Athfal. The result of this study indication thatcorrelation between work Environment and job satisfaction are very significant, correlation between Teamwork and job satisfaction is significant and finally correlation between work Environment and Teamwork in collective to lecture's job satisfaction have regression line equation and it is able to test in corrective. Therefore, this correalation should be maintained and developed to achieve better than relations so as to provide benefits for teachers and Raudhatul Athfal, as more and better relationship, so higher the job satisfaction.
\end{abstract}

Keywords: Job Satisfaction, Job Environment, Team Work

\section{PENDAHULUAN}

Kepuasan kerja (job satisfaction) merupakan sikap yang timbul berdasarkan penilaian terhadap situasi tempat dimana ia bekerja. Kepuasan kerja ini juga mencerminkan perasaan seseorang terhadap pekerjaannya. Ini nampak dalam sikap positif karyawan terhadap tugastugas yang diberikan dan segala sesuatu yang dihadapi di lingkungan kerjanya sebagai sekumpulan perasaan kepuasan yang bersifat dinamis.

Dalam organisasi, pertentangan-pertentangan bisa saja terjadi antara para karyawan. Hal itu terjadi karena banyaknya manusia yang ada dalam organisasi itu dikarenakan masingmasing mempunyai sifat, sikap, keinginan, kepribadian dan minat yang berbeda-beda. Salah satu ciri dari suatu kelompok yang matang adalah kemauan dan kemampuannya untuk mengangkat perselisihan yang ada keatas permukaan sehingga bisa dibicarakan dan memberi kemungkinan penyelesaian yang lebih besar. Ada banyak macam konflik yang membawa implikasi dan jika tidak ditangani dengan baik akan berlanjut pada stress dan tekanan yang dirasakan oleh karyawan dan pada akhirnya akan menyebabkan produktivitas dan kepuasan kerja karyawan menjadi menurun.

Menyikapi hal tersebut maka lingkungan kerja sebagai penentu dalam suatu organisasi merupakan hal yang paling penting dalam menentukan kebijakan suatu kondisi organisasi atau dengan kata lain maju mundurnya suatu organisasi sangat dipengaruhi oleh lingkungan kerjanya.

Berdasarkan wawancara intensif yang telah dilakukan peneliti terhadap guru-guru diwilayah Duren Sawit Jakarta Timur, rasa ketidakpuasan guru banyak disebabkan oleh

* Staf Pengajar di SDIT AL-KARIMAH Duren sawit Jakarta Timur 
berbagai faktor diantaranya adalah pemenuhan kebutuhan atau finansial yang kurang mencukupi, hubungan sosial, kepribadian, nilai, etika, lingkungan kerja, kerjasama tim, motivasi kerja dan lain-lain.

Ada beberapa unsur penting untuk terciptanya suatu kepuasan kerja diantaranya, pemenuhan kebutuhan, pengembangan karier, adanya penghargaan dan lain-lain. Bila dikaitkan dengan kepuasan kerja dari segi materiil, jelas diketahui bahwa hasil yang diterima dari pekerjaan guru masih relatif kecil. Hal ini jika dibandingkan dengan jenis pekerjaan lain dengan status pendidikan yang sama diketahui pula bahwa penghasilan mereka jauh diatas guru Walaupun disisi lain, adapula yang berpenghasilan dibawah penghasilan guru. Sehingga puas dan tidak puasnya seorang karyawan tergantung dari beberapa faktor salah satunya lingkungan kerja, kerja sama tim dan beberapa faktor penting lainnya.

Lingkungan kerja dapat mempengaruhi kepuasan kerja jika kondisi lingkungannya menarik ataupun bersih, itu semua akan menjadikan individu dapat lebih mudah untuk menyelesaikan pekerjaan mereka. Akan tetapi jika lingkungan kerjanya buruk maka individu akan sulit pula untuk menyelesaikan tugas-tugas yang telah diberikan kepadanya. Sehingga dalam lingkungan kerja harus seoptimal mungkin tercipta lingkungan kerja yang baik.

Lingkungan kerja dapat diartikan sebagai segala sesuatu yang ada disekitar para pekerja dan dapat mempengaruhi dirinya dalam menjalankan tugas yang dibebankan. Adapun hal-hal lain yang ditemui ditempat kerja adalah sebagai berikut:

1) Adanya penerapan aturan kebijakan sekolah yang kurang disetujui guru, 2) Adanya pembagian rezeki yang kurang seimbang hal ini terjadi berkaitan dengan pembagian kerja yang ada dananya antar sesama guru berbeda-beda, 3) Tempat kerja yang berpotensi, baik dari suara, sarana maupun prasarana yang secara langsung maupun tidak langsung berkaitan dengan pekerjaan guru menjadi penyebab kenyamanan dan ketidaknyamanan seseorang untuk bekerja.

Lingkungan kerja yang baik disertai dengan kerja sama tim yang baik juga dapat saling mempengaruhi kepuasan kerja. Sedangkan kerja sama tim yang kuat bertindak sebagai sumber dukungan, kenyamanan, nasihat dan bantuan pada anggota individu. Tim adalah sekelompok orang yang enerjik dengan membangun dan membentuk kerjasama guna memperoleh hasil dengan kualitas tertinggi.

Berdasarkan masalah yang terjadi, maka peneliti tertarik untuk meneliti "Hubungan Lingkungan Kerja dan Kerja Sama Tim Dengan Kepuasan Kerja" (Studi Korelasional pada Guru Raudhatul Athfal di Wilayah Duren Sawit Jakarta Timur )

\section{Kepuasan Kerja}

Kepuasan kerja merupakan suatu hal yang positif dalam meningkatkan kualitas kerja di setiap tempat orang bekerja, sehingga kenyamanan dan tingkat kualitas kerja dapat diukur dengan mengetahui seberapa puas seseorang menekuni pekerjaannya, adapun dibawah ini penjelasan tentang kepuasan kerja itu sendiri yang dikutip dari teori Luthan adalah sebagai berikut:

Locke gives a comprehensive definition of job satisfaction as involving cognitive, affective and evaluative reactions or attitudes and states it is a pleasurable or positive emotional state resulting from the appraisal of one's job or job experience. job satisfaction is a result of employees' perception of how well their job provides those things that are viewed as important. ( Locke dalam Luthan memberikan definisi yang komprehensif dari kepuasan kerja sebagai melibatkan kognitif, reaksi afektif dan evaluatif atau sikap dan menyatakan itu adalah "suatu keadaan emosional yang menyenangkan atau positif yang 
dihasilkan dari penilaian terhadap pekerjaan atau pengalaman kerja. kepuasan kerja merupakan hasil dari persepsi karyawan sebesar seberapa baik pekerjaan mereka menyediakan hal-hal yang dianggap penting ).

Menurut definisi lain yang dikutip pada buku Stephen P Robbins bahwa kepuasan kerja adalah suatu perasaan positif tentang pekerjaan seseorang yang merupakan hasil dari sebuah evaluasi karakteristiknya.

Adapun menurut Kinicki yang menjelaskan tentang kepuasan kerja bahwa " Job satisfaction an affective or emotional response toward various facets one's job". ( Kepuasan kerja merupakan respon afektif atau emosional terhadap berbagai segi pekerjaan seseorang).

Sedangkan menurut Sopiah Dalam berbagai teori dan pendekatan bahwa perlu diketahui bagaimana cara mengukur kepuasan kerja tersebut, ada beberapa cara untuk mengukur kepuasan kerja diantaranya: Menggunakan skala indeks deskripsi jabatan (Job description indeks), Dengan menggunakan kuisioner kepuasan kerja Minnesota (Minnesota satisfaction Questionare) dan,Pengukuran berdasarkan ekspresi wajah .

Sementara itu, Greenberg dan Baron menunjukkan adanya tiga cara untuk melakukan pengukuran kepuasan kerja.yaitu: Rating skala dan kuesioner, Rating skala dan kuesioner merupakan pendekatan pengukuran kepuasan kerja yang paling umum dipakai dengan menggunakan kuesioner dimana rating skala secara khusus disiapkan. Dengan menggunakan metode ini, orang menjawab pertanyaan yang memungkinkan mereka melaporkan reaksi mereka pada pekerjaan mereka.

Berdasarkan deskripsi toeri di atas, yang dimaksud dengan Kepuasan kerja guru adalah Tindakan dari perasaan senang terhadap pekerjaan seseorang yang dihasilkan dari penilaian terhadap pekerjaannya. dengan indikator: (1) Rasa Senang dalam bekerja, (2) Rasa dihargai, (3) Rasa memiliki, (4) Bersemangat dalam bekerja, (5) Menyukai pekerjaan.

\section{Lingkungan kerja}

Menurut Lynton Keith Caldwell yang dikutip Ndaraha dalam Environment: A Challenge for Modern Society (The American Museum of Natural History Press,NY,1970), Lingkungan adalah keseluruhan yang mengitari, termasuk yang dikitari yaitu manusia yang bersangkutan, lingkungan berfungsi sebagai sumber daya yang dapat dibedakan menjadi (1) lingkungan alam yang berfungsi menjadi sumber daya alam. Daya duukung SDA semakin merosot mendekati nol atau semakin terbatas; (2) lingkungan manusia yang berfungsi sebagai sumber daya manusia; dan (3) lingkungan buatan yang berfungsi sebagai sumber daya buatan.

Menurut Laurie J. Mullin ada beberapa faktor yang berhubungan dengan lingkungan kerja yaitu sebagai berikut: Bentuk tugas, pengaturan fisik, komunikasi, dan teknologi.

Menurut Cohen adanya beberapa faktor penekanan lingkungan yang mempengaruhi seseorang dalam bekerja sehingga dapat mengalami tekanan atau gangguan psikologis, fisik maupun perilaku.

Berdasarkan uraian di atas maka disimpulkan bahwa lingkungan kerja adalah lingkungan kerja adalah kondisi fisik dan dan psikologis tempat seorang bekerja dengan indikator: (1) Kenyamanan kerja, (2) Keharmonisan hubungan dengan karyawan lain, (3) Kelengkapan Peralatan kerja, (4) Kenyamanan ruangan, (5) Kelengkapan alat teknologi Informasi, (6) Dukungan dari atasan, (7) Peranan solideritas dari teman sejawat.

\section{Kerja Sama Tim}

Sebuah organisasi yang terlibat dalam Total Quality Management akan memperoleh manfaat dengan memiliki tim-tim yang efektif disemua tingkatan. Tim adalah dua orang atau lebih yang secara suka ela bekerja sama untuk mencapai hasil-hasil yang bermutu. 
Menurut Schermerhorn bahwa kerjasama Tim ialah Work Team is Occurs when group members work together in ways that utilize their skill well to accomplish a purpose. (Kerjasama Tim adalah Kegiatan ketika anggota kelompok bekerja sama dalam cara-cara yang menginspirasikan keahlian mereka dengan baik untuk mencapai tujuan).

Menurut Gross ada 4 variabel yang penting dalam sistem hubungan kerja antara lain: Pendirian lembaga, Pola status dan kekuasaan, Riwayat hidup individu-individu, Sifat kelompok-kelompok pekerjaan yang berhadapan, Menurut Dunlop, ia menggambarkan model dan berlainan, ia menentukan 3 kelompok yang penting dalam suatu organisasi yang berubah salah satunya tergantung dengan pegawai, manajer dan lingkungan kerja serta masyarakat kerja.

Didalam organisasi sebaiknya sebagai pegawai ataupun anggota harus saling berkomunikasi hal ini tidak dapat dipisahkan dalam keterkaitan kerja, hubungan kerja yang lama harus diperbaharui agar terciptanya hubungan kerja yang harmonis terhadap semua anggota.

Adapun untuk menjadikan sebuah tim menjadi sukses dalam pembentukan suatu tim tidak dengan sendirinya akan berjalan sebagaimana yang diharapkan. Untuk itu diperlukan usaha mengatasi faktor-faktor yang dapat menghambat kesuksesan kerjasama tim dan dibutuhkan pula berbagai upaya agar tim dapat mencapa misi dan tujuan pembentukan, King ( dalam Goetsch dan Davis 1994,pp218-219) mnenganjurkan 10 strategi yang ia sebut sepuluh perintah Tim ( Ten Team Commandments) untuk meningkatkan kinerja suatu tim dalam rangka pencapaian tujuan organisasi, dan adapun kesepuluh strategi tersebut ialah saling ketergantungan, perluasan tugas, penjajaran, bahasa yang umum, kepercayaan, kepemimpinan, keterampilan pemecahan masalah, keterampilan menangani konflik, tindakan dan perayaan.

Berdasarkan deskripsi teori di atas, yang dimaksud dengan kerjasama tim adalah Sekelompok masyarakat yang bekerja sama dengan tujuan yang jelas dalam memberikan perubahan yang baik dalam pekerjaannya, dengan indikator: (1) Saling Percaya, (2) Keterbukaan, (3) Kesediaan untuk berbagi, (4) Antusiasme dalam Tim, (5) Kekompakan.

\section{Metode Penelitian}

Metode yang digunakan dalam penelitian ini adalah metode survei dengan pendekatan korelasional untuk menguji hubungan antar variabel yang akan di uji hubungannya yaitu: Kepuasan kerja sebagai variabel terikat $(Y)$, Lingkungan kerja sebagai variabel bebas pertama (X1), dan kerjasama tim sebagai variabel bebas (X2). Penelitian dilaksanakan pada Raudhatul Athfal (RA) Duren Sawit Jakarta Timur, data penelitian akan dikumpulkan pada bulan September s/d Oktober 2010, instrumen pada penelitian dilakukan ini dengan cara pengumpulan dan analisis data yang diambil dari 115 guru yang akan diambil datanya melalui random sampling dengan sampel 60 guru.

\section{HASIL PENELITIAN DAN PEMBAHASAN}

\section{Hubungan antara Lingkungan kerja dengan kepuasan kerja}

Dari hasil analisis korelasi sederhana antara lingkungan kerja dengan kepuasaan kerja, diperoleh koefisien korelasi sebesar 0,620 (ry1 = 0,620). Koefisien determinasi (r2y1) adalah sebesar 0,385. Ini menunjukkan bahwa 38,5\%.

Hasil perhitungan koefisien korelasi parsial menunjukkan ry1.2 sebesar 0,522. Dengan demikian bahwa koefisien korelasi antara kepuasan kerja $(\mathrm{Y})$ dengan lingkungan kerja $(\mathrm{X} 1)$ jika kerjasama tim (X2) dikontrol, "berarti dan tidak dapat diabaikan", sehingga hipotesis nol yang diajukan dalam penelitian ini ditolak, sebaliknya hipotesis alternatif diterima. Kesimpulannya adalah terdapat hubungan antara lingkungan kerja (X1) dengan kepuasan 
kerja (Y). hal ini sejalan dengan pendapat teori James L. Gibson yang menyatakan bahwa adanya hubungan antara lingkungan kerja dan meghasilkan pada kepuasan kerja.

\section{Hubungan antara kerjasama tim dengan kepuasan kerja}

Hasil analisis korelasi sederhana antara kerjasama tim dengan kepuasaan kerja dapat diperoleh koefisien korelasi sebesar 0,577 ( ry2 $=0,577$ ). Nilai ini memberikan pengertian bahwa terdapat hubungan antara kerjasama tim dengan kepuasan kerja. Koefisien determinasi adalah sebesar 0,333. Ini menunjukkan bahwa 33,3\% variasi yang terjadi pada kepuasan kerja.

Hasil perhitungan koefisien korelasi parsial menunjukkan ry2.1 sebesar 0,459. Dengan demikian bahwa koefisien korelasi parsial antara kepuasan kerja $(Y)$ dan kerjasama tim $(X 2)$, jika Lingkungan kerja (X1) dikontrol, "berarti dan tidak dapat diabaikan" sehingga hipotesis nol yang diajukan dalam penelitian ini ditolak, sebaliknya hipotesis alternatif diterima. Kesimpulan: terdapat hubungan antara kerjasama tim dengan kepuasan kerja (Y). Hal ini sejalan dengan teori Kinicki yang menjabarkan pada bagan bahwa adanya hubungan terhadap kerjasama Tim yang didukung oleh sekelompok tim kerja yang menghasilkan kepada kepuasan kerja.

\section{Hubungan Antara Lingkungan kerja dan Kerjasama tim dengan Kepuasan kerja}

Hasil analisis korelasi ganda antara lingkungan kerja dan kerjasama tim dengan kepuasaan kerja dapat diperoleh koefisien korelasi ganda sebesar 0,717 (ry.12=0,717). Nilai ini memberikan pengertian terdapat hubungan antara Lingkungan kerja dan kerjasama tim secara bersama-sama dengan kepuasan kerja. Koefisien determinasi (r2) adalah sebesar 0,514. Ini menunjukkan bahwa 51,4\% variasi yang terjadi pada kepuasan kerja dapat dijelaskan oleh Lingkungan kerja dan Kerjasama tim secara bersama-sama dengan kepuasan kerja.

Hasil diatas sejalan dengan Jennifer M Goerge yang menyatakan dalam berupa bagan bahwa adanya hubungan Lingkungan kerja dan kerjasama Tim dengan kepuasan kerja.

\section{PENUTUP}

Kesimpulan : 1) Terdapat hubungan positif antara lingkungan kerja dengan kepuasan kerja. Hal ini menandakan bahwa akan terjadi kepuasaan kerja jika lingkungan kerja nyaman serta kelengkapan peralatan untuk mempermudah dalam meningkatkan kualitas dalam bekerja. 2) Terdapat hubungan positif antara kerjasama tim dengan kepuasan kerja. Hal ini menandakan bahwa kerjasama tim yang menghasilkan kepuasan kerja jika selalu bekerja sama dalam menyelesaikan setiap pekerjaan serta solideritas antara rekan kerja yang selalu didukung dengan komunikasi aktif antara rekan kerja lainnya sehingga terjalinnya kekompakan dalam suatu tim. 3) Terdapat hubungan positif antara lingkungan kerja dan kerjasama Tim dengan Kepuasan kerja. Berdasarkan persamaan regresi dapat disimpulkan bahwa peningkatan satu nilai lingkungan kerja diikuti peningkatan kepuasan kerja, apabila variabel lingkungan kerja dalam keadaan konstan.

Implikasi : 1) Peningkatan Kepuasan kerja akan berimplikasi pada rendah dan tingginya semangat, komunikasi untuk bertahan dalam suatu lembaga, meningkatnya kualitas kerja, tingginya loyalitas yang menimbulkan dampak pada kinerja dan produktivitas yang meningkat. 2) Lingkungan kerja akan berdampak baik jika didukung oleh adanya kondisi manusia yang memperhatikan adanya lingkungan sebagai pengaruh dalam aktifitasnya sehingga komunikasi, alat-alat pendukung dan pengaturan fisik dapat memberikan kenyamanan terhadap guru sehingga hubungan harmonis antara guru dan rekan kerjanya dapat tercipta dengan baik sebagai pendukung dari lingkungan kerja harus diperhatikan agar menghasilan nilai yang positif terhadap hasil pekerjaan. 
Saran : (1) Upaya peningkatan lingkungan kerja dalam rangka peningkatan Kepuasan kerja. (2) Upaya peningkatan kerjasama tim dalam rangka peningkatan kepuasan kerja. (3) Upaya peningkatan lingkungan kerja dan kerjasama tim secara bersama-sama dengan kepuasan kerja.

\section{DAFTAR PUSTAKA}

Fandy,Diana, Total Quality Management, Andi,Yogyakarta,2003.

Fredh Luthan ,Organizational Behavior, The McGraw-Hill Companies, New York, 2008.

Kinicki, Organization Behavior Key concepts, skill and best practices. New York : Mc Graw-Hill, 2003.

Laurie J. Mullins, Management and Organizational Behaviour, Prentice Hall Financial Time, England ,2005.

Ndraha. T, Budaya Organisasi. Jakarta: Rineka Cipta,2003.

Robert Kreitner and Angelo Kinichi, Organizational Behavior, McGraw hill International, Edition,Singapore,2007.

Stephen P Robbins, Perilaku Organisasi (edisi terjemahan), Jakarta, Salemba Empat 2007.

Veithzal Rivai, Education Manajement Analisis teori dan Praktik, PT Rajawali Grafindo Persada, Jakarta, 2009.

Schermerhorn, Organizational Behavior, Wiley, United State Of America, 2003. 
